The 16th Economic International Conference

New Challenges and Opportunities for the Economy 4.0, May 7-8th, 2020, Suceava, Romania

\title{
Valencies of the University of Entrepreneuriality in The Matrix of Sustainable Economy: Challenges and Opportunities
}

\author{
Daniela Mihaela NEAMTU, Angela Nicoleta COZORICI, \\ Cristian Valentin HAPENCIUC
}

https://doi.org/10.18662/lumproc/ncoe4.0.2020/22

How to cite: Neamtu, D.M., Cozorici, A.N., \& Hapenciuc, C.V. (2020). Valencies of the University of Entrepreneuriality in The Matrix of Sustainable Economy: Challenges and Opportunities. In C. Nastase (vol. ed.), Lumen Proceedings: Vol. 13. 16th Economic International Conference NCOE 4.02020 (pp. 252-264). Iasi, Romania: LUMEN Publishing House. https://doi.org/10.18662/lumproc/ncoe4.0.2020/22 


\title{
Valencies of the University of Entrepreneuriality in The Matrix of Sustainable Economy: Challenges and Opportunities
}

\author{
Daniela Mihaela NEAMTU1*, Angela Nicoleta COZORICI², \\ Cristian Valentin HAPENCIUC ${ }^{3}$
}

\begin{abstract}
The objectives of the study refer first and foremost to establishing the role of universities to become a potential agent for change towards sustainability. The research analysis allowed us to explore whether:

1. Stefan cel Mare University offered students the opportunity to develop skills that allowed them to actively respond to entrepreneurial challenges;

2. To what extent students are involved in activities related to the entrepreneurial development offered by the university;

3. The research of the most desired skills by the business environment from the students' point of view will enrich the empirical analysis. I undertook an exploratory research, the results of which we processed using SPSS v.20.

The research results have practical implications for universities and can support the advancement of educational programs related to sustainable development.
\end{abstract}

Keywords: entrepreneurship; entrepreneurial university; skills; stakeholders.

\footnotetext{
1 "Stefan cel Mare" University, Suceava, Romania, dana neamtu99@yahoo.com

2 "Stefan cel Mare" University, Suceava, Romania, cozoriciangela@yahoo.com

3 "Stefan cel Mare" University, Suceava, Romania, expresedinte@gmail.com 
Daniela Mihaela NEAMTU, ... | Lumen Proceedings 13 | NCOE4.0 2020

\section{Introduction}

Being - or becoming - an entrepreneurial higher education institution is a reaction to these considerations. There is no "one-size-fits-all" approach, but many ways in which higher education institutions can have an entrepreneurial component - for example, the way they manage their resources and build their organizational capacity, the way it involves all stakeholders in administrative activities and leadership, in which it creates and nurtures the synergy between teaching and research activities and social involvement, but also in which it promotes entrepreneurship through education, support for start-ups, exchange of experience and information to improve the capacity of innovation within companies already operating on the market.

According to Kirzner, entrepreneurship is "... a constant effort of a businessman to identify and use every opportunity to make a profit" [1], while according to Ronstadt it is a process of incremental wealth [2]. Schumpeter [3] and Ronstadt [2] agree that an entrepreneur is an innovative person who takes the risk of dedicating personal will and time to identify and combine resources and skills in order to add value to a product or service [2]. Hisrich and Peters argue that an entrepreneur devotes time and effort to creating something new, which has value due to the financial, psychological and social risk assumed [4].

The EU is increasingly emphasizing the "third mission" of universities, in addition to the two traditional knowledge creation (research) and knowledge transfer (education) missions, which use research results and transfer them to different companies. The current cohesion policy of the EU, based on smart specialization strategies and addressing the "quadruple helix" [5] [6] [7], mainly aimed at research, technology and innovation, further promotes the role of universities as key factors of regional development. The updated agenda for tertiary education highlights that universities should pay more attention to the relationship between different stakeholders in the regional ecosystem and align all their actions with regional smart specialization strategies. The process of entrepreneurial discovery is probably the most important "tool" and the driving force of smart specialization strategies, because it allows interested parties to interact to discover the areas of regional strategic potential.

This article examines the contribution of universities for supporting entrepreneurship at regional level, as well as the role of universities in regional development. Secondly, it attempts to register the role of Stefan cel Mare University through a first collection and processing of information 
and actions regarding entrepreneurship / innovation in the matrix of regional entrepreneurial universities.

According to the World Economic Forum, the main pillars of an entrepreneurial matrix are human resources, the study programs of the big universities that promote entrepreneurship and the prevailing business culture (risk tolerance and failure, presentation of the most successful businesses and innovation in society, etc.). Systems for the support of entrepreneurs - mentors and consultants, access to national and international markets, funding means, state (legislative and regulatory framework and infrastructure), education and training (provision of qualified human resources) [8].

\section{The Valencies of the Entrepreneur University}

If we resort to a study on the modern concept of "Entrepreneurial University" we find out that there is no unitary definition for it. For all that, when describing the concept, one should take into consideration the seven aspects - characteristics that the majority of the definitions attribute to the "Entrepreneurial University": entrepreneurship development in the teaching and learning process, entrepreneurship platforms, leadership and governance, organizational capacity, people and incentives, extern relationships between university and business for knowledge exchange, "Entrepreneurial University" in the position of an internationalized institution and measuring the impact of "Entrepreneurial University" [9].

The model of entrepreneurial university [12] is the answer to the research question What kind of university we need today in order to best meet the needs of the turbulent environment which we live in (Figure 1), while integrating the points of view about the characteristics of entrepreneurial university of various authors [10], [11] with the knowledge on functioning of entrepreneurially oriented organisations. In the context of academic and environmental subjects, entrepreneurialism can be seen as the development of a set of individual behaviours, skills and attitudes as characterised by the entrepreneur [13]. We can apply the same characteristics to the intrapreneur, the social entrepreneur, the technopreneur and across many other contexts. However, we need to show why is this concept so important? Which is the real importance of entrepreneurship in higher education? Are all these concepts relevant for higher education institutions? Is HEI stimulating entrepreneurship across its campus? Why is it so important to have an entrepreneurial university? 


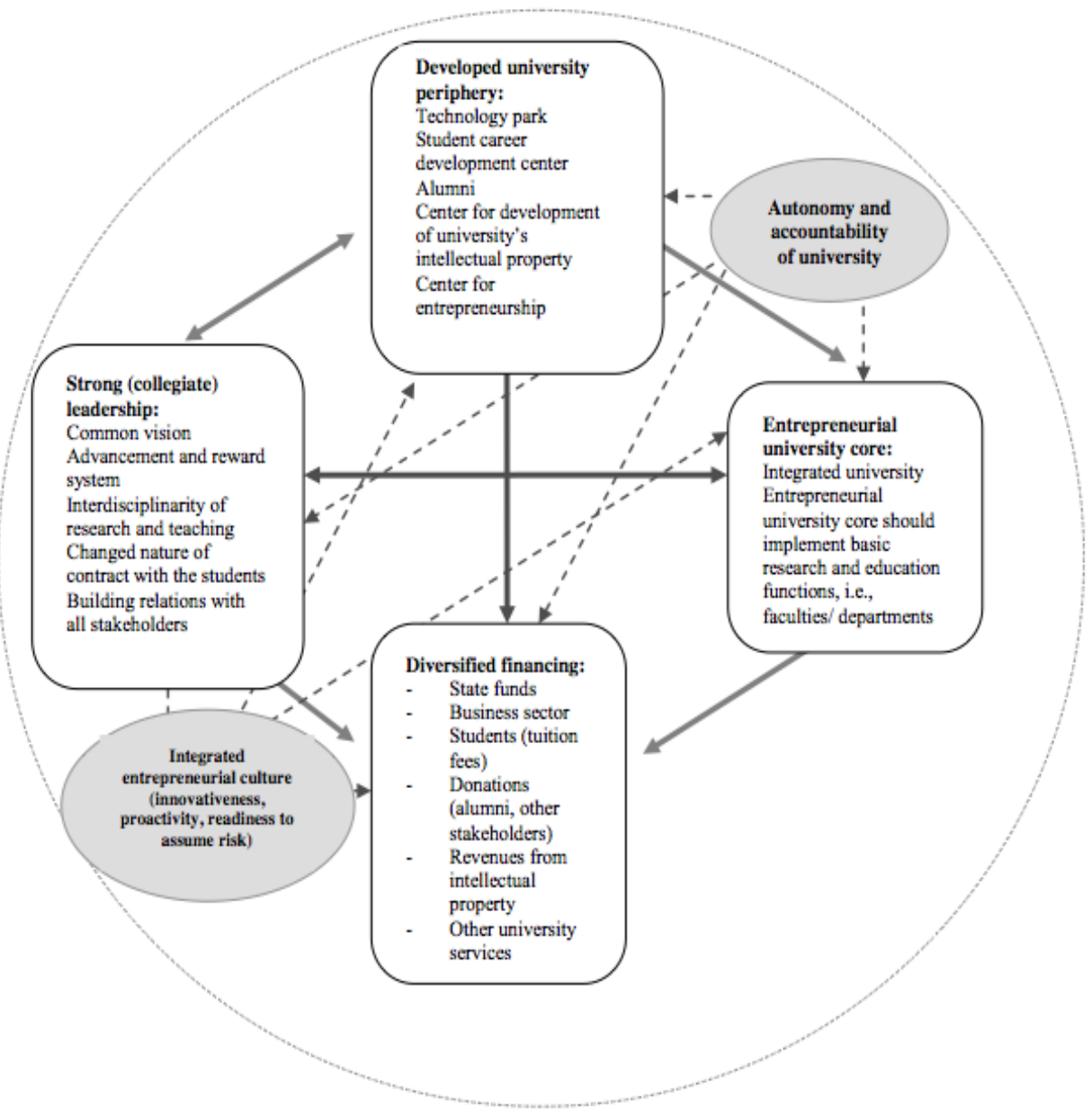

Fig.1. Model of entrepreneurial university

Source: [12]

1. Core components: Entrepreneurial university basis consists of university components performing the basic research and education functions (such as: faculties, departments...), and the structure of integrated university, which is supra organized.

2. The project-oriented and interdisciplinary research centres of an university, working on the transfer of university's knowledge and technology to the business community (applied research), are concentrated in the university periphery, with the role of developing and taking care of university's intellectual property, organising and implementing (in cooperation with other university departments) continuous education programs (Lifelong Learning), assisting the university in fundraising 
activities, developing contacts with the alumni, improving the development of their students' careers, and organising activities and establishing contacts with university's environment.

3. Strong (collegiate) leadership; we point out the importance of university leadership capacity in the creation of entrepreneurial university. In the process of university transformation, strong leadership is vital. Thus, there is no chance that transformation to entrepreneurial university will take place, if university leadership doesn't embrace the concept of entrepreneurial university. Collegial leadership supports the creation of governance structure, while motivating and encouraging all parts of the university to be proactive and to adapt an enterprising behaviour, achievement of team goals being ahead of realization of personal goals ("we" vs. "I").

4. Diversified financing; financial independence (on state sources of financing) of a university is an important premise in the process of creating an entrepreneurial university. A sense of controlling one's own destiny is being supported by financial independence; in our case, it enables the university to launch and implement projects according to its own necessities and priorities, while preventing, at the same time, undesired commercialisation of university services, as it provides the freedom to choose projects.

For the entrepreneurship development in teaching and learning in European "Entrepreneurial Universities" we rely on typical examples such as the following: EM Lyon Business School (France), which is being structured in such a manner that it could support entrepreneurship learning, forming "skills and attitudes to become an entrepreneur" [14]; The University of Wismar (Germany) aiming to disperse the entrepreneurial spirit through the integration of a set of skills in the study programs [15] University of Applied Sciences Jena (Germany) which supports entrepreneurial behaviour from generation to generation, through the Center for Innovation and Entrepreneurship, and increases awareness and stimulates the ideas until they reach development and implementation [16]; Aalborg University (Denmark) which operates the entrepreneurial support program that supports, facilitates and motivates knowledge-based entrepreneurship and prepares students for a career after their studies as entrepreneurs, through training, mentoring, coaching and providing infrastructure support [17]; moreover, a group of Finnish universities, including the University of Tampere (Finland) that integrated innovation projects with Demola (an open, Finnish, innovation platform that offers support from teachers and specialists in the industry to multidisciplinary student teams, [18] etc.

The individual or collective innovation, ranging from students to academics, can be seen in the "Entrepreneurial University", a place where 
knowledge and skills are provided at a deeper level than at other levels of education. Furthermore, in the context of university entrepreneurship education, personal programs and skills are mixed with practical business training [19].

Since the development and economic dynamics of nowadays society rely on the combination of four interdependent elements, namely the production of new knowledge, its transmission through education and training, its dissemination using information and communications technology and its use through new industrial processes or services, this new dynamic brings to light the universities, as true protagonists. [20]

\section{Research Methodology}

Our research had as a starting point the principle of triangulation (triangulation strategy) in the context of a dynamic and complex reality in the socio-human field, which requires the corroboration of several theoretical, methodological perspectives and the study of several data sources, in order to obtain a complete and valid image of the reality proposed for analysis.

3.1 The investigated community consists of the students of "Stefan cel Mare" University of Suceava, from the final years of the bachelor's and master's cycles because, knowing the cause, we considered that this way we maximize the chances of obtaining relevant answers. The research method used as a tool for data collection was a questionnaire - with online administration. This study represents only part of a larger research, which also addresses other variables, factorial analyzes and broad statistical correlations, which was accepted for publication in another specialized journal [21]. In this study we focused only on what the entrepreneurial university matrix means for a sustainable economy.

3.2 The variables proposed for analysis were:

Academic skills and competences - there were used12 items that measure the university competences and abilities formed as a result of the academic programs of the FSEAP Suceava. The items were coded on a scale from 1 (very small measure) to 5 (very large measure) and participants were asked to indicate the extent to which they believe they have trained their respective skills and competences. The test results indicated high values of the Alpha Cronbach coefficients is 0.843 , proving good internal consistency.

Perception on the bachelor / master program - there were used 5 items coded on a scale from 1 (very small measure) to 5 (very big measure). 
Daniela Mihaela NEAMTU, ... | Lumen Proceedings 13 | NCOE4.0 2020

The qualities of a successful entrepreneur - 8 items that refer to the traits that ensure success in entrepreneurship measured this variable. Items were coded on a scale of 1 (very small measure) to 5 (very big measure). Data analysis considered each item separately and did not consider the scale as a whole.

The relevance of the researched theme is justified on the basis of the following research hypotheses:

\subsection{Hypotheses:}

1. There will be significant differences regarding the perception of the bachelor / master program depending on the evaluative indicators of the programs.

2. There will be a significant positive correlation between university skills and competences and the perception of the bachelor / master program.

3. There is a significant positive correlation between university skills and competencies and the qualities of a successful entrepreneur.

3.4 Processing and interpretation of results

Table 1. Descriptive data on the levels of the variable perception on the bachelor / master program

\begin{tabular}{rlccc}
\hline Crt. & Itemi & N & Mean & SD \\
\hline 1. & Employers are aware of the skills & 348 & 3.83 & 0.90 \\
\hline 2. & The good academic reputation of the program & 348 & 4.20 & 0.82 \\
\hline 3. & Having the possibility to occupy a wide range of & 348 & 4.14 & 0.88 \\
& positions after graduation & & & \\
\hline 4. & Oriented to vocational training & 348 & 4.08 & 0.95 \\
\hline 5. & Preparation for academic research & 348 & 3.85 & 0.96 \\
\hline
\end{tabular}

To verify Hypothesis 1 we performed a One-Way ANOVA analysis in SPSS. The results indicated that the averages regarding the perception on the bachelor / master program vary significantly depending on the levels of the variable. Specifically, the results indicated that there are differences between the medium levels of the variable $[\mathrm{F}(4,1735)=12.281, \mathrm{p}=0.000]$.

- [employers'awareness about the skills] and [good academic reputation of the program] (Mdiff $=-.3316$, Str. Err. $=.068, \mathrm{p}=.000)$ 
- [employers'awareness about the skills] and [Having the posibility to ocupy a wide range of positions after graduation] (Mdiff $=-.373$, Str. Err. $=$ $.068, \mathrm{p}=.000)$

- [Employers'awareness about the skills] and [Oriented to vocational training] (Mdiff $=-.255$, Str. Err. $=.068, \mathrm{p}=.002$ )

- [Great academic reputation of the program] and [reparation for academic research] $($ Mdiff $=.287$, Str. Err. $=.068, \mathrm{p}=.000)$

- [Having the possibility to occupy a wide range of positions after graduation] and [reparation for academic research] (Mdiff $=-.373$, Str. Err. $=.068, \mathrm{p}=.000)$

- [Preparation for academic research] and [reparation for academic research] $($ Mdiff $=-.227$, Str. Err. $=.068, \mathrm{p}=.009)$

There were no significant differences between the other levels of the variable.

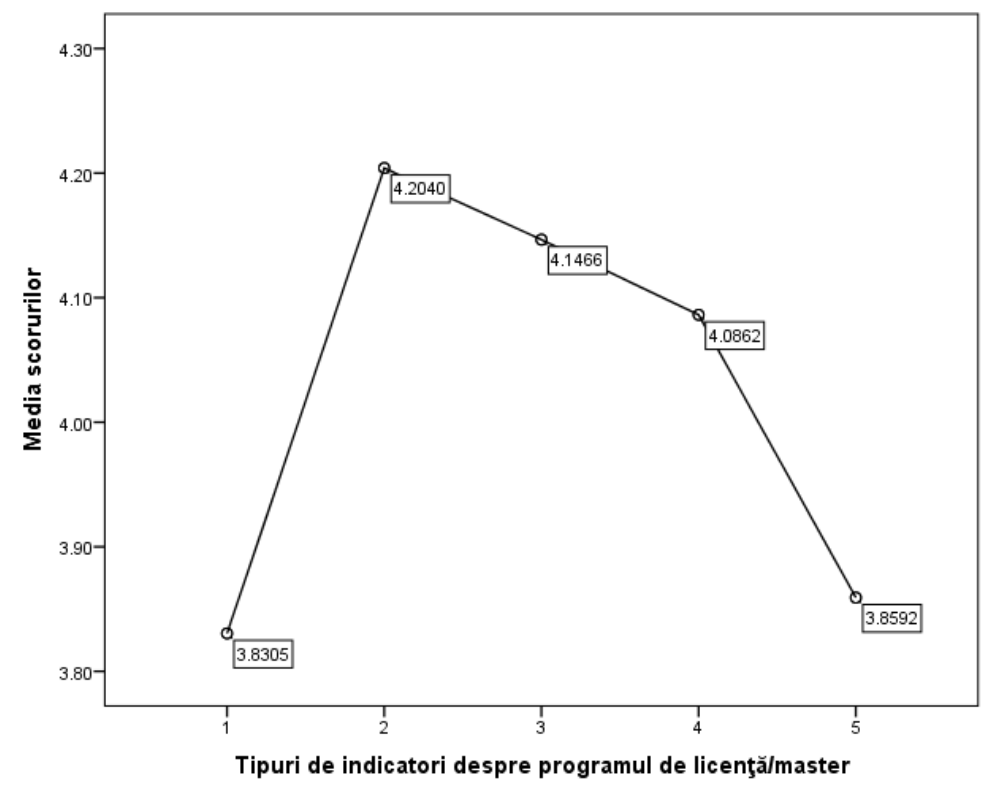

Figure 2. Average scores according to the perception of the indicators about the bachelor and master program.

To test hypothesis 2 we applied Pearson correlation analysis in SPSS. A composite score was obtained from the 5 indicators of perception on the master/license program for the analysis. The results indicated that there is a significant positive correlation between the two variables: $(\mathrm{r}=.563, \mathrm{p}=.000$, $\mathrm{N}=348$ ). The effect is significant (see Cohen 1988). The hypothesis is 
Daniela Mihaela NEAMTU, ... | Lumen Proceedings 13 | NCOE4.0 2020

confirmed. The visual representation of the results is presented in the Scatter graph no.3.

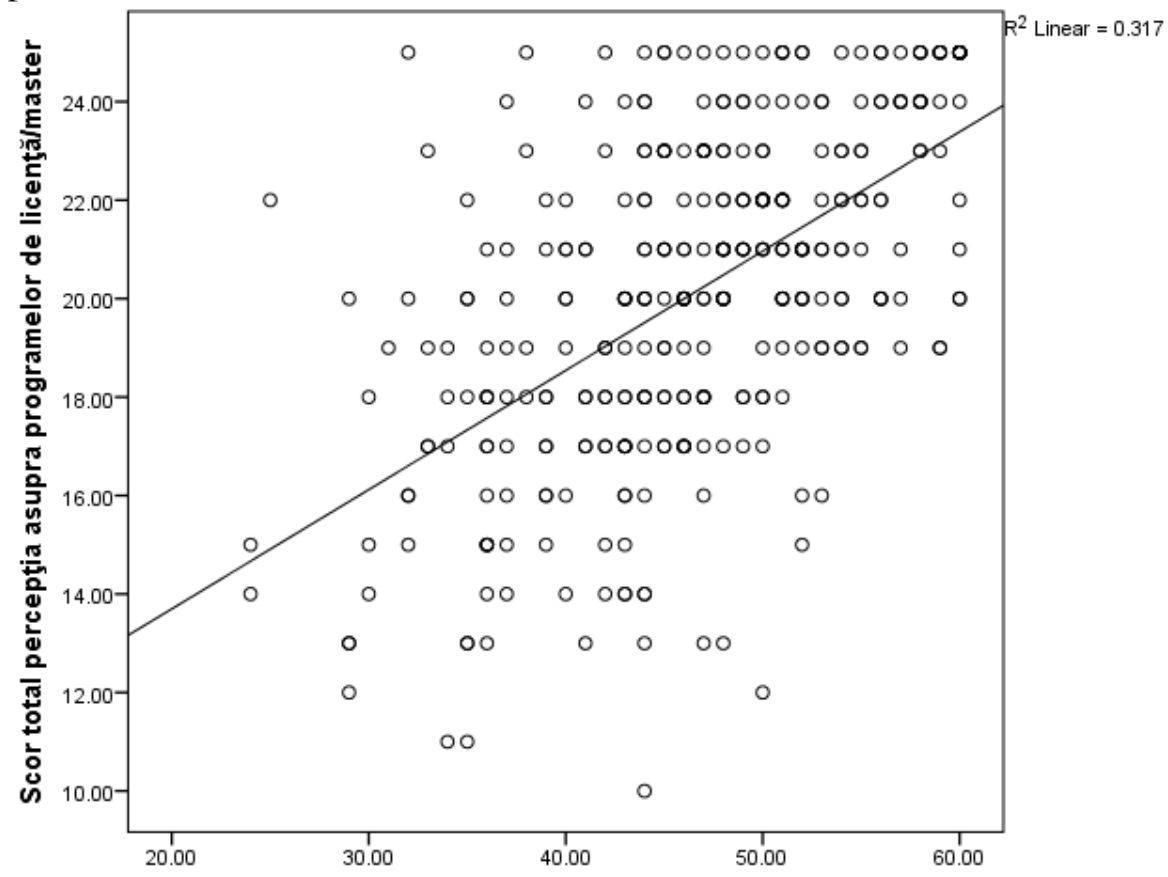

Abilităţi şi competenţe academice

Figure 3. Scatter graph on the Pearson correlation between the two variables.

In other words, as respondents' perception of the bachelor's and master's programs improves, academic skills and competences also increase. To test the third hypothesis, we performed a multiple Pearson correlation analysis. The results indicated that there are significant associations between the variable skills and academic competencies and the variables that make up the qualities of a successful entrepreneur (see Table 2).

\begin{tabular}{rlr}
\hline \multicolumn{1}{c}{ Itemi } & Rezultatele analizei de corelaţie \\
\hline 1. & I take responsibility for my work & $\mathrm{r}=.335, \mathrm{p}=.000,348$ \\
\hline 2. & I am proactive and I like to work. & $\mathrm{r}=.351, \mathrm{p}=.000,348$ \\
\hline 3. & I have a tolerance (medium or low) & $\mathrm{r}=.194, \mathrm{p}=.000,348$ \\
& at risk. \\
\hline 4. & I have leadership abilities & $\mathrm{r}=.381, \mathrm{p}=.000,348$ \\
\hline 5. & Creativity and innovation & $\mathrm{r}=.415, \mathrm{p}=.000,348$ \\
\hline 6. & Passion for your won ideas & $\mathrm{r}=.326, \mathrm{p}=.000,348$
\end{tabular}




\begin{tabular}{rll}
\hline 7. & Tenacity & $\mathrm{r}=.400, \mathrm{p}=.000,348$ \\
\hline 8. & Trust & $\mathrm{r}=.410, \mathrm{p}=.000,348$ \\
\hline 9. & Continuous learning & $\mathrm{r}=.361, \mathrm{p}=.000,348$ \\
\hline
\end{tabular}

The results indicate that there are significant correlations between the analyzed variables. The hypothesis is confirmed.

\section{Results and Discussions}

On the one hand, the results indicate that the good academic reputation of the program, the possibility of occupying a wide range of positions after graduation, the orientation towards the professional training of the university programs does not differ from the point of view of the average scores. On the other hand, the knowledge of the competencies by the employer or the preparation for the academic research obtained both results significantly worse than the other three items.

On the other hand, the correlation analysis shows that as respondents' perceptions about the bachelor's or master's degree program improve, academic skills and competences also increase.

Then, the results indicated that academic skills and competences are closely related to the well-known personality traits that ensure success in entrepreneurship. Confirmation of this hypothesis, by the fact that significant correlations were obtained between the analyzed variables, underlines that the guarantee of success in business is the cooperation between personality traits and the facilities available from the university. The assimilation of academic skills and competences within the business faculty is the result of the convergence between the features absolutely necessary for business success and an educational context favorable to their assimilation.

In general, students declared themselves satisfied with their participation in the entrepreneurship actions. The survey indicated their satisfaction with the organization of open seminars and the hours related to entrepreneurship and innovation, but also to the provision of consultation and guidance. It was also observed that students are requesting the extension of the university's collaboration framework with the private sector as well as the existence of dual education where they can combine entrepreneurship courses with specialized internships. Of course, there is always room for improvement, especially in terms of acquiring skills and experience (for example, developing innovative business plans and visiting entities that incorporate innovations into their operation). 
Some weaknesses have been revealed regarding the initiation of an entrepreneurial activity, but which allows the university to investigate more deeply these directions indicated by the students, so that they can respond by effective methods and tools to mitigate / eliminate these fears.

\section{Conclusions}

Higher education institutions have a unique position in society. Higher education institutions represent spaces of particular importance due to the production, dissemination and dissemination of knowledge. In addition to these conventional associations between universities and acquaintances, higher education institutions have the unique potential to encourage the synthesis and integration of different types of knowledge and to amplify the application of knowledge for the purpose of social change. In terms of a social transition to sustainability, the main role of higher education institutions can be considered in two ways: universities can be perceived as institutions that need to be changed or can be perceived as a potential agent of change.

In the current context, the success of students as entrepreneurs is a strategic objective for the "Stefan cel Mare" University of Suceava, which reconfigured the curricula and introduced courses and seminars on entrepreneurship education, initiated projects under the aegis of the Business Incubator, of the Centers of Business Research in Business Management and Administration and implements projects for setting up start-ups in the North-East region of the country. Stefan cel Mare University of Suceava is defined as "a reference pillar of the integrative approach in the university, public administration and community formed by economic and social actors" (USV Mission). Entrepreneurship remains the most efficient driver of a dynamic, competitive and innovative economy.

\section{Acknowledgements}

This work is supported by project POCU 125040, entitled "Development of the tertiary university education to support the economic growth - PROGRESSIO", co-financed by the European Social Fund under the Human Capital Operational Program 2014-2020 
Daniela Mihaela NEAMTU, ... | Lumen Proceedings 13 | NCOE4.0 2020

\section{References}

[1] Kirzner I. Competition and Entrepreneurship. Chicago: University of Chicago Press; 1973.

[2] Ronstadt. Entrepreneurship: Text, Cases \& Notes. Dover: Lord Pub. Business \& Economics; 1984.

[3] Schumpeter JA. The Theory of Economic Development. Cambridge: Harvard University Press; 1934.

[4] Hisrich R, Peters M. Entrepreneurship, 5th ed. New York: McGraw Hill Irwin; 2002.

[5] European University Association. The Role of Universities in Smart Specialization Strategies. Report on Joint EUA-REGIO/JRC. Brussels: EUA Publications; 2014.

[6] Committee of the Region. Using the Quadruple Helix Approach to Accelerate the Transfer of Research and Innovation Results to Regional Growth; 2014. Available online: http://cor.europa.eu/en/documentation/studies/ Documents/quadruplehelix.pdf (accessed on 14 February 2020).

[7] Park, HW. Transition from the triple Helix to N-Tuple Helices? An Interview with Elias Carayiannis and David F., J., Campbell. Scientometrics. 2014; 99: 203-7.

[8] World Economic Forum. Entrepreneurial Ecosystems around the Globe and Company Growth Dynamics. Davos: World Economic Forum. 2014, pp. 6-7.

[9] EC, and OECD. A Guiding Framework for Entrepreneurial Universities; $2012 . \quad$ Available online: www.oecd.org/site/cfecpr/ECOECD $\% 20$ entrepreneurial $\% 20$ Universities $\% 2$ OFramework.pdf

[10] Clark B. Creating Entrepreneurial Universities, IAU and Elsevier Science, Paris and Oxford;1998.

[11] Gibb A. Towards the Entrepreneurial University, Entrepreneurship Education as a lever for change, National Council for Graduate Entrepreneurship, UK; 2005.

[12] Oberman P. Poduzetnicka sveucilista u funkciji efektivne diseminacije intelektualnog vlasnistva sveucilista [The role of entrepreneurial universities in disseminating its intellectual property], Doctoral Dissertation, J.J. Strossmayer University in Osijek, Croatia; 2008.

[13] Hannon PD. Why is the Entrepreneurial University Important? Journal of Innovation Management; JIM. 2013, 1, 2: 10-17.

[14] EM Lyon Business School. Entrepreneurship Incubation; 2019. Available from: www.em-lyon.com/en/Entrepreneurship-Incubation (accessed on 14 January 2020).

[15] Hochschule Wismar. Degree Courses Taught in English. Wismar: University of Applied Sciences, Technology, Business and Design Wismar; 2019. Available from: www.hs-wismar.de/en 
[16] Ernst-Abbe-Hochhule Jena. Center for Innovation and Entrepreneurship, University of Applied Sciences Jena; 2019. Available from: www.eahjena.de/de-de/forschung_/Documents/Flyer_CIE_2015.PDF

[17] Aalborg University. Supporting Entrepreneurship at Aalborg University; 2019. Available from: www.sea.aau.dk

[18] Demola. The Global University Alliance; 2019. Available from: www.demola.net

[19] Neamțu DM. The University - An Entrepreneurial and Innovative Higher Education Institution, 11th International Technology, Education and Development Conference, INTED 2017 Proceedings, 6-8 March, Valencia Spain; 2017. doi: 10.21125/inted.2017.2088

[20] Hapenciuc CV, Bejinaru R., Roman C, Neamtu DM. The Role Of HES Within The Evolution Of The Business Sector, EDULEARN- 8th annual International Conference on Education and New Learning Technologies Barcelona (Spain). 4th - 6th of July, 2016, EDULEARN 16 Proceedings; 2016, pp. 5309-5317

[21] Neamtu DM, Bejinaru R, Hapenciuc CV, Condratov I, Stanciu, P. Analysis and Modeling of Influence Factors in the Configuration of a Sustainable University. Case Study: Stefan cel Mare University of Suceava, Jurnalul Amfiteatrul Economic, Sustainable University; 2020; 22(54): 264 - 282. 